\title{
Interobserver Agreement in MR Enterography for Diagnostic Assessment in Patients with Crohn's Disease
}

\author{
Interobserver-Übereinstimmung bei der MR-Enterografie in der Diagnostik \\ bei Patienten mit Morbus Crohn
}

Authors

Affiliations
S. Schleder ${ }^{1}$, M. Pawlik ${ }^{2}$, P. Wiggermann ${ }^{1}$, C. Ott ${ }^{3}$, S. Fichtner-Feigl ${ }^{4}$, R. Müller-Wille ${ }^{1}$, C. Stroszczynski ${ }^{1}$, A. G. Schreyer ${ }^{1}$

Department of Radiology, University Hospital Regensburg, Germany

Department of Anesthesiology, Caritas Hospital St. Josef, Regensburg, Germany

Department of Internal Medicine I, University Hospital Regensburg, Germany

Department of Surgery, University Hospital Regensburg, Germany

\author{
Key words \\ - abdomen \\ - ileum \\ - efficacy studies \\ - inflammation \\ - statistics \\ - MR imaging
}

eingereicht 25.12 .2012

akzeptiert 13.3.2013

Bibliography

DOI http://dx.doi.org/

10.1055/s-0033-1335445

Published online: 26.7.2013

Fortschr Röntgenstr 2013; 185 :

992-997 @ Georg Thieme

Verlag KG Stuttgart · New York .

ISSN 1438-9029

\section{Correspondence \\ Dr. Stephan Schleder}

Department of Radiology,

University Hospital Regensburg,

Germany

Franz-Josef-Strauß-Allee 11

93053 Regensburg

Tel.: ++ 49/9 41/9447401

Fax: ++49/941/9447402

Stephan.Schleder@ukr.de

\section{Abstract \\ $\nabla$}

Purpose: To evaluate the extent to which MRE can be used as an observer-independent, objective imaging method for the diagnosis and evaluation of $C D$ with respect to the detection of inflammatory changes of the small bowel and lymphadenopathy as diagnostic criterion and bowel distension as a quality criterion.

Materials and Methods: MRE scans of 84 patients (42 female, median age 37 years) were evaluated independently by 4 experienced radiologists. Analysis of inflammatory changes of the bowel wall, lymphadenopathy and adequate bowel distension was conducted separately for the jejunum, ileum and terminal ileum. The Kendall's W-test was used for the statistical comparison of concordance.

Results: In a total of 55 patients, inflammatory activity of the bowel wall was detected and MRE was found to have a high interobserver reproducibility concerning inflammatory changes of the intestinal wall (Kendall's W $0.527-0.823$ ). Concerning lymphadenopathy (31 cases, 36.9\%), a low to moderate consensus could be shown with a Kendall's W value of $0.402-0.505$. For the assessment of adequate bowel distension, a moderate concordance between the operators could be found (Kendall's W 0.497 - 0.581).

Conclusion: MRE has proven high interobserver agreement with respect to the diagnosis of inflammatory disease activity of the bowel as a diagnostic criterion in patients with $C D$. Concerning adequate bowel distension as a quality criterion of the examination itself and lymphadenopathy as a diagnostic criterion, moderate interobserver agreement could be found. This is thought to have a rather small effect on the diagnostic significance and conclusiveness of the method in the daily routine.
Key Points:

- MR enterography as observer independent diagnostic procedure in patients with Chron's Disease.

- Highest interobserver concordance for the criterion of inflammatory bowel wall affection.

- Moderate interobserver concordance for lymphadenopathy and bowel distension.

Citation Format:

- Schleder S, Pawlik M, Wiggermann P etal. Interobserver Agreement in MR Enterography for Diagnostic Assessment in Patients with Crohn's Disease. Fortsc hr Röntgenstr 2013; 185: 992-997

\section{Zusammenfassung}

$\nabla$

Ziel: Zu evaluieren, inwieweit die MR-Enterografie (MRE) bezüglich der Beurteilung entzündlicher Dünndarmwandveränderungen und der Lymphadenopathie als Diagnosekriterium und der Darmdistension als Qualitätskriterium eine untersucherunabhängige objektive Methode in der Diagnostik des Morbus Crohn (MC) darstellt. Material und Methoden: Es wurden die MRE von 84 konsekutiven Patienten (42 weiblich, Median 37 Jahre) von 4 erfahrenen Radiologen unabhängig voneinander analysiert. Dabei wurde von jedem Auswerter für das Jejunum, Ileum und terminale Ileum beurteilt, ob eine entzündliche Darmwanveränderung, eine Lymphadenopathie und eine diagnostisch adäquate Darmdistension vorlagen. Um die Übereinstimmung der Diagnose der einzelnen Radiologen untereinander zu überprüfen, wurde der Kendall-W-Test verwendet.

Ergebnisse: Bei insgesamt 55 Patienten (65,5\%) wurde entzündliche Aktivität festgestellt, die MRE weist bezüglich entzündlicher Darmwandveränderungen eine hohe Untersucherunabhängigkeit 
(Kendall-W 0,527 - 0,823) auf. Betrachtet man die Lymphadeopathie (31 Fälle, 36,9\%), findet sich eine geringe bis moderate Übereinstimmung mit Kendall-W-Werten 0,402-0,505. Eine ebenso moderate Übereinstimmung der Untersucher findet sich für die Darmdistension (Kendall-W 0,497-0,581), welche insgesamt als sehr gut bewertet wurde.

Schlussfolgerung: Die MRE stellt beim MC eine Methode mit hoher Interobserver-Übereinstimmung bezüglich der Diagnose entzündlicher Dünndarmabschnitte als Indikator der Diagnosequalität dar. Bezüglich der Darmdistension als Indikator der Untersuchungsqualität sowie der Lymphadenopathie besteht eine lediglich moderate Übereinstimmung, welche in der klinischen Praxis die hohe und objektive Aussagekraft der Methode nicht relevant beeinträchtigen dürfte.

\section{Introduction}

In addition to conventional radiological double-contrast examination such as enteroclysis [1, 2], abdominal sonography (US) $[3,4]$, computed tomography (CT) $[5,6]$, and magnetic resonance imaging (MRI) [7-11] can be used for the primary or relapse diagnosis of patients with Crohn's disease (CD) via radiological imaging. Each of the indicated examination methods has various advantages and disadvantages. With respect to the primary diagnosis of $C D$, the current German S3 guideline regarding the $\mathrm{CD}$ diagnosis states that no single examination method can represent the gold standard $[12,13]$.

The current European guidelines also describe the importance of all of the methods with preference being given to MRI [14], which with the current technical developments has the advantage of being able to image the entire small and large bowel with high spatial and temporal resolution without the use of radiation. This method is therefore specified in the guidelines of the German Society for Digestive and Metabolic Diseases (DGVS) in addition to US as the preferred radiological basic diagnostic method for CD.

MRI of the small bowel with oral contrast, referred to in the literature as MR enterography (MRE), is a method that has been established in numerous studies, is well tolerated, and can visualize all relevant pathologies in patients with $C D$ with high sensitivity and specificity [15 - 17]. In addition, it is possible to draw conclusions about possibly present extraluminal complications, such as abscesses or fistulas, that can be missed by endoscopic methods or conventional radiological double-contrast methods [3, 18-20].

MRE is also in excellent agreement with current clinical score systems such as the Montreal classification regarding the evaluation of the disease with respect to inflammation, stenosis, or perforating processes [21]. It is therefore suitable for representing the basic radiological examination for further decisions regarding medication-based or surgical treatment concepts.

In contrast to sonographic diagnosis of the small bowel, evaluation of the bowel via MRI has a high level of objectivity while being able to visualize the entire abdomen and small bowel [22].

However, there is currently little data regarding the diagnostic objectivity and observer independence of MRE even though these play a decisive role with respect to the objectivity of the examination as well as the repeatability and com- parability of the results $[23,24]$. The objective of the study is therefore to evaluate the extent to which MRE can be used as an observer-independent, objective imaging method for the diagnosis and evaluation of $C D$ with respect to the detection of inflammatory changes of the small bowel wall and lymphadenopathy as diagnostic criterion and bowel distension as a quality criterion.

\section{Materials and Methods \\ $\nabla$}

\section{Patient collective}

In the present study, 84 consecutive patients (42 women, 42 men, mean age: 37 years) were included prospectively and were examined in the case of histologically proven $C D$ with MRE for initial diagnosis or for follow-up. There was no contraindication for MRE in any patient. A study entitled “Sequenz-Evaluation für die MR-Enterografie für Patienten mit Morbus Crohn" [Sequence Evaluation for MR Enterography for Patients with Crohn's Disease] [25] was already performed using the same collective.

\section{MR examination procedure}

All patients had been fasting for at least 12 hours at the time of the examination. To distend the bowel and to generate a hypointense intraluminal signal in the T1-weighted sequence ("dark lumen technique"), the patients drank two liters of water with an additional $25 \mathrm{~g}$ mannitol and $5 \mathrm{~g}$ carob bean gum (Nestargel; Nestlé Deutschland AG, Frankfurt am Main, Germany) per liter within an hour. Just prior to the examination, the patients received $200-300 \mathrm{ml} \mathrm{NaCl} 0.9 \%$ as a rectal contrast for additional distension of the rectum [26, 27]. Moreover, all patients received $40 \mathrm{mg}$ butylscopolamine (Buscopan, Boehringer Ingelheim Pharma GmbH \& Co. KG, Ingelheim am Rhein, Germany) intravenously just prior to the examination. In our experience the duration of effect of the butylscopolamine over all acquired sequences was adequate to reduce movement and to distend the bowel so that we were able to use a single intravenous dose. There were no contraindications for any of the evaluated patients. In the contrast-enhanced T1-weighted sequences, a dose of $0.1 \mathrm{mmol} / \mathrm{kg}$ body weight of Gd-DTPA (Magnevist, Schering AG, Berlin, Germany) was administered intravenously.

The examination was performed on a $1.5 \mathrm{~T}$ MRI unit with a gradient field strength of $20 \mathrm{mT} / \mathrm{m}$ (Symphony, Siemens Medical Systems, Erlangen, Germany). Coronal T2/T1weighted sequences (TrueFISP, True Fast Imaging With Steady Precession, TR/TE 4.76/2.38 msec, flip angle $60^{\circ}$, matrix 256, FOV $450 \mathrm{~mm}$, measurement time $19 \mathrm{~s}$ ) with a slice thickness of $5 \mathrm{~mm}$ were first acquired followed by axial T2weighted turbo spin echo sequences (HASTE, Half FourierAcquired Single Shot Turbo Spin Echo, TR/TE 1070/77 msec, flip angle $150^{\circ}$, matrix 256, FOV $400 \mathrm{~mm}$, breath-triggered, measurement time $109 \mathrm{~s}$ ) with a slice thickness of $8 \mathrm{~mm}$. In addition, axial, fat-saturated, T1-weighted gradient echo sequences (2D-FLASH, Fast Low Angle Shot, TR/TE 124/ $4.7 \mathrm{msec}$, flip angle $70^{\circ}$, matrix 256 , FOV $380 \mathrm{~mm}$ ) with a slice thickness of $6 \mathrm{~mm}$ were acquired before (measurement time $72 \mathrm{~s}$ ) and after Gd-DTPA administration (measurement time $119 \mathrm{~s}$ ). The sequence protocol ended with coronal, fat-saturated, T1-weighted gradient echo sequences (2D-FLASH, Fast Low Angle Shot, TR/TE 86/4.7 msec, 
flip angle $70^{\circ}$, matrix 256, FOV $380 \mathrm{~mm}$, measurement time $90 \mathrm{~s}$ ) with a slice thickness of $5 \mathrm{~mm}$.

Both the selected sequences and the indicated sequence parameters correspond to the routine MRI protocol at our institute and have been optimized and established over years with more than 200 patients with chronic inflammatory bowel diseases being examined by MRE each year.

\section{Diagnosis and evaluation}

All MR acquisitions were analyzed independently by four experienced radiologists. The four evaluators were radiologists with at least three years of abdominal diagnostics experience.

\section{Inflammatory small bowel change}

Evaluation was performed under consideration of all available MRI sequences. Every examiner evaluated whether there was an inflammatory change of the jejunum, ileum, and terminal ileum. For this purpose bowel wall thickening with a diameter of more than $3 \mathrm{~mm}$ and contrast uptake of the bowel wall were defined as direct signs of inflammation. Increased vascular injections and the presence of pathological lymph nodes were indirect signs of inflammation ( Table 1 ). In the case of a lack of direct and indirect signs of inflammation, a "0: no inflammation" was assigned, in the case of a corresponding single finding and a positive lymph node finding, a " 1 : uncertain inflammation" was assigned, in the case of two or more of the radiological signs of inflammation, a "2: definite inflammation" was assigned as the MRE evaluation.

\section{Lymphadenopathy}

The presence of a perifocal mesenterial lymphadenopathy was detected independently of the above criteria in the case of the presence of lymph nodes with a short axis diameter greater than $1 \mathrm{~cm}$. In addition, clustered lymph nodes were evaluated as lymphadenopathy independently of their diameter. An accumulation of 3 or more lymph nodes was evaluated as a cluster. The presence of a lymphadenopathy was assigned to the jejunum, ileum, and the terminal ileum according to the above described small bowel topology.

\section{Bowel distension}

The distension of the small bowel as a quality criterion of the examination was evaluated with " 0 : none" in the case of adequate distension of the bowel segment in less than $50 \%$ of the segment (jejunum, ileum, terminal ileum). In the case of adequate distension of the segment in approximately $50-80 \%$ of the segment length, the segment was evaluated with " 1 : minor" and with " 2 : good" in the case of $80 \%$ distension in the segment $[28,29]$.

Table 1 Criteria for diagnosing inflammation of the small bowel.

criteria for diagnosing inflammation
bowel wall thickening of more than $3 \mathrm{~mm}$
increased contrast uptake of the bowel wall compared to the surrounding
bowel
vascular injections
lymphadenopathy (lymph nodes $\geq 1 \mathrm{~cm}$ or cluster $\geq 3$ lymph nodes)

\section{Statistical methods}

The program SPSS version 16.0 (SPSS Inc., Chicago, IL, USA) for Windows (Microsoft, Redmond, WA, USA) was used for the statistical tests.

To check the agreement of the diagnoses of the individual radiologists among one another, the Kendall's W test was used. The calculated concordance coefficient $W$ is in a value range of $0-1$. A value $W=0$ indicates no agreement and a value $\mathrm{W}=1$ indicates complete agreement. $\mathrm{W}=$ between 0 and 0.482 indicates minor agreement, between $0.482-0.7$ indicates moderate agreement and a value $W=0.7$ or higher indicates significant agreement.

\section{Results}

$\nabla$

\section{Inflammatory small bowel change}

According to the division of the small bowel into the jejunum, ileum, and terminal ileum, all four radiologists excluded inflammation in 29 of 84 (34.5\%) patients; in 2 $(2.4 \%)$ cases uncertain signs of inflammation were diagnosed by all four radiologists; and definite inflammatory activity was determined in 18 (21.5\%) more of the evaluated cases by all four radiologists ( $\bullet$ Fig. 1 ). In the remaining $35(41.7 \%)$ cases, no agreement regarding the presence of inflammation was achieved.

For the criterion "inflammatory small bowel change", the Kendall's W values were as follows: 0.527 for the jejunum, 0.724 for the ileum, and 0.823 for the terminal ileum. The

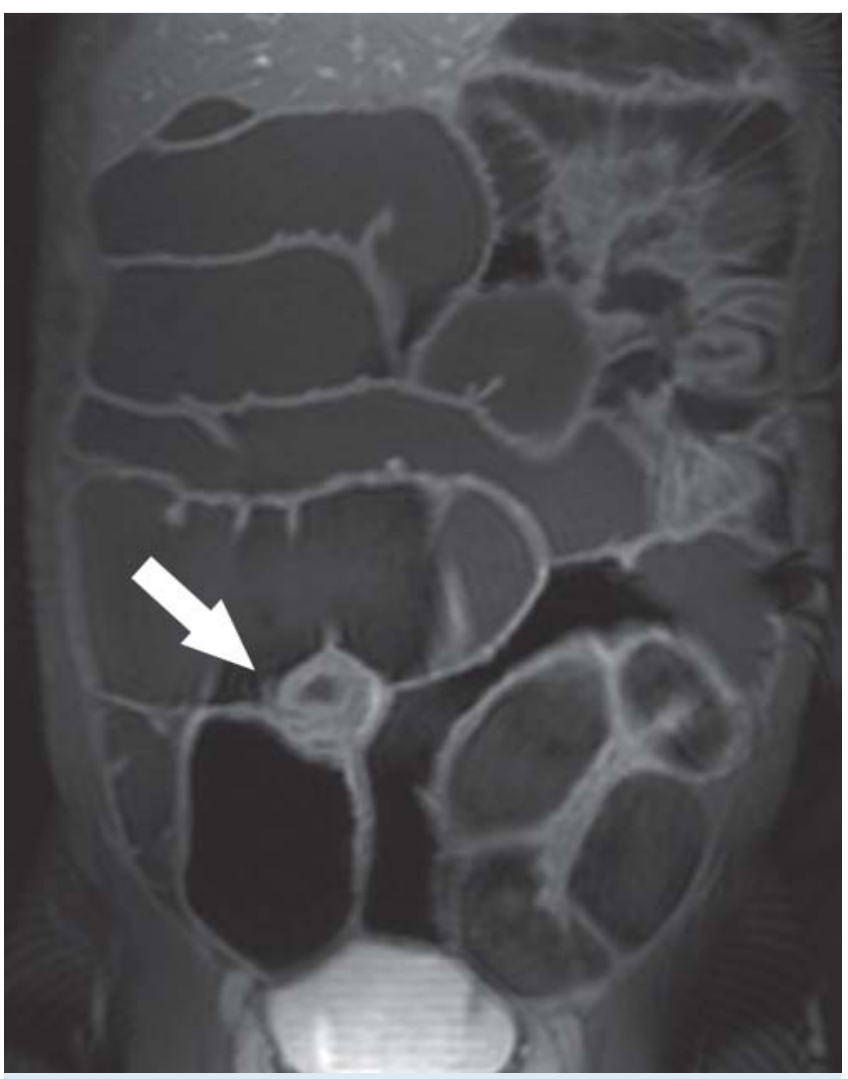

Fig. 1 Coronal contrast-enhanced fat-saturated T1-weighted gradient echo sequence: Inflammatory stenosed ileal loop with prestenotic and poststenotic dilation marked by a white arrow. 


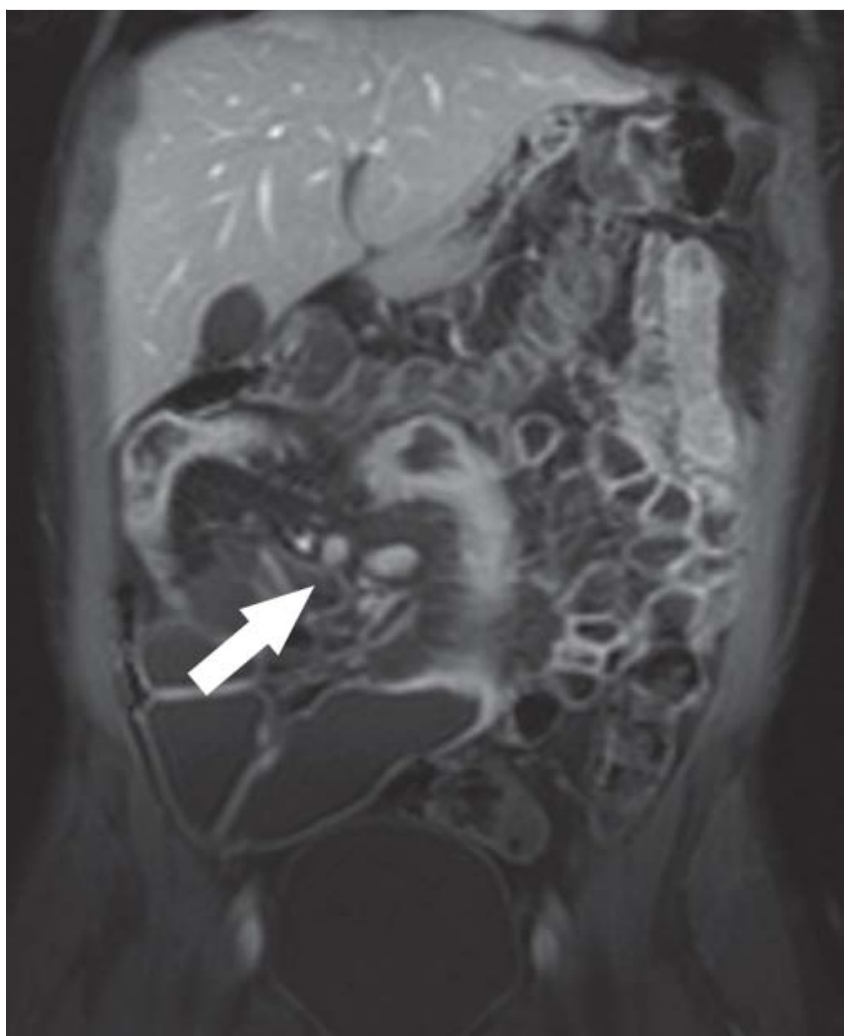

Fig. 2 Coronal contrast-enhanced fat-saturated T1-weighted gradient echo sequence: Lymphadenopathy around the terminal ileum marked by a white arrow.

Table 2 Evaluation of the "bowl distension" criterion by four radiologists.

\begin{tabular}{lllll} 
in bowel & \multicolumn{2}{l}{ evaluation of distension } & Kendall's W ${ }^{1}$ \\
\cline { 2 - 5 } segment & $\mathbf{2 5 \%}$ quartile & Median & $\mathbf{7 5 \%}$ quartile & \\
\hline jejunum & $50-80 \%$ & $50-80 \%$ & $>80 \%$ & 0.497 \\
ileum & $50-80 \%$ & $>80 \%$ & $>80 \%$ & 0.581 \\
\hline terminal ileum & $50-80 \%$ & $>80 \%$ & $>80 \%$ & 0.566
\end{tabular}

${ }^{1}$ A Kendall's $W$ value $=0$ indicates no agreement and a value $W=1$ means complete agreement. $W=$ between 0 and 0.482 indicates minor agreement, between 0.482 and 0.7 indicates moderate agreement and a value $W=0.7$ or higher indicates significant agreement.

examination method and the evaluation therefore exhibit high observer independence in this regard.

\section{Lymphadenopathy}

In $53(63.1 \%)$ cases, the presence of lymph nodes was unanimously dismissed and was equally unanimously confirmed in 3 (3.6\%) cases. In the remaining 28 (33.3\%) examinations, the four radiologists produced differing evaluations ( $\bullet$ Fig. 2). The Kendall's W value for the criterion "lymphadenopathy" is on the border to low or average agreement and is 0.402 for the jejunum, 0.505 for the ileum, and 0.505 for the terminal ileum.

\section{Bowel distension}

At least 50 - 80 \% bowel distension ( $\bullet$ Fig. 3) was achieved in all segments. A distension of over $80 \%$ was even achieved in the jejunum and terminal ileum according to the evalua-

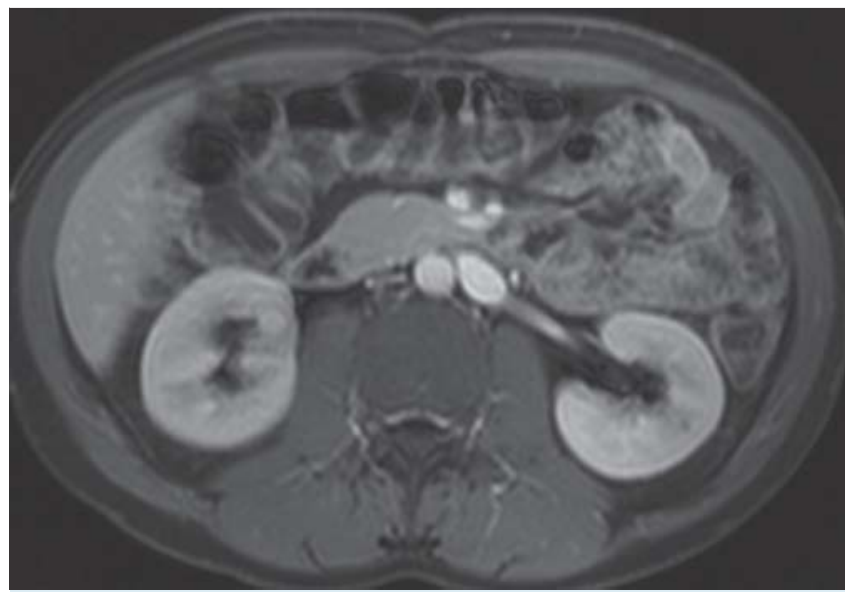

Fig.3 Transverse contrast-enhanced fat-saturated T1-weighted gradient echo sequence: In agreement among the four radiologists, the bowel distension was evaluated with " 1 : slight (50-80\%)".

tions of the four radiologists ( $\bullet$ Table 2 ). The median value for the relevant segment was " 2 : good".

The evaluations of the four radiologists yielded Kendall's W values of 0.497 for the jejunum, 0.581 for the ileum and 0.566 for the terminal ileum.

\section{Discussion}

The results of this study show a high level of objectivity and observer independence for MRE for the criterion of inflammatory small bowel changes. This is particularly true for the ileum (Kendall's W 0.724) and the terminal ileum (Kendall's W 0.823) and also for the jejunum (Kendall's W 0.527) with moderate observer independence. However, the inferiority of MRE in the jejunum compared to other diagnostic methods, such as capsule endoscopy, is already known [30]. With respect to the examination quality, there is only average agreement of the evaluations for the criterion of bowel distension with Kendall's W values between 0.497 for the jejunum and 0.581 for the ileum. The lowest level of agreement was achieved regarding a perifocal lymphadenopathy. The Kendall's W values are only between 0.402 and 0.505 for this case.

In contrast to the previously published literature, not only the presence or absence of inflammatory bowel wall changes was analyzed in the present study but also the inflammatory affection of bowel segments according to anatomical small bowel segments was evaluated as definite, uncertain, or not present by four different experienced evaluators. As in previous studies, there was no gold standard for evaluating the correctness of the results of MRI diagnoses. Rather the goal of the study was to evaluate the objectivity of the radiological examination modality already established in the guidelines.

The merely moderate agreement of the evaluation of the examination quality in relation to bowel distension is difficult to interpret. The intentionally subjectively selected evaluation criterion of "adequate" distension in the Materials and Methods section was probably the reason for the partially divergent interpretation of the term "adequate". Therefore, this subjective and divergent evaluation may be due to the differ- 
ent intraindividual demands and experience with respect to examination quality. However, the selected categorization (adequate distension of the relevant bowel segment to approximately $50-80 \%$ of the segment length was evaluated with "1: minor" and distension of the relevant bowel segment to over $80 \%$ was evaluated with "2: good" $[28,29])$ allows significant room for subjectivity.

With respect to the decisive question regarding inflammatory bowel affection, the four experienced evaluators in this study were able to achieve a high level of agreement for the terminal ileum and ileum. In the case of CD, small bowel involvement is present in these bowel segments in most cases. The merely moderate agreement in the jejunum should only be of secondary clinical relevance in clinical practice due to the extremely rare isolated occurrence of the disease in this segment. The poor ability to evaluate small bowel affections in the proximal small bowel was already able to be shown by Gölder et al. in a comparison study of MRE with capsule endoscopy [30].

Previous studies of the interobserver variability of MRE by Jensen et al. involving 50 patients with confirmed or suspected $\mathrm{CD}$ focusing on the comparison of MRE with CT enterography already showed moderate observer independence $(\mathrm{K}=0.48)$ for the diagnosis of small bowel involvement in $C D$ [23]. These results are confirmed by the present study and are even exceeded with an overall high observer independence. A more precise analysis of the study data shows that the slightly lower results of $\mathrm{k}=0.48$ was probably due to a single outlier of the four evaluators. The different small bowel segments were also not sufficiently differentiated in this study.

Schmidt et al. also calculated a moderate observer independence for the thickening of the bowel wall $(k=0.48)$ for 50 patients examined with MR enteroclysis due to unclear intestinal complaints. The study was also primarily designed to compare MR enteroclysis with the CT-based technique. However, the study did not exclusively include patients with CD [31]. Only 34\% of the examined patients had a chronic inflammatory bowel disease. The remaining patients were examined due to small bowel tumors, bleeding, postoperative complications, or for other reasons.

With respect to the criterion of lymphadenopathy, there was no adequate observer independence $(\mathrm{K}=0.15)$ in the study by Schmidt et al. [31]. However, the criterion of lymphadenopathy was selected to be very small with a lymph node diameter starting at $0.5 \mathrm{~cm}$. In our study a significantly higher observer independence with an average Kendall's W value of 0.482 was able to be achieved with respect to the diagnosis of lymphadenopathy using other criteria (lymph nodes $\geq 1 \mathrm{~cm}$, cluster) but this still does not yield a reliable degree of agreement. Overall, the limited ability to assess lymphadenopathy in CD compared to CT examination has already been shown in other studies [31-34].

\section{Conclusion}

$\nabla$

In patients with Crohn's disease, MR enterography has proven to be an objective and stable radiological examination method with excellent interobserver agreement regarding the diagnosis of inflammatory small bowel segments. The merely moderate agreement of different evaluators regard- ing bowel distension as an indicator of examination quality and a lymphadenopathy as an indirect inflammation criterion should not impact the high and stable objectivity of the method in clinical practice.

\section{References}

1 Maataoui A, Reusch E, Khan MF et al. Comparison of analog and digital fluoroscopy devices regarding patient radiation exposure in enteroclysis. Fortschr Röntgenstr 2008; 180: 246-251

2 Schunk K, Metzmann U, Kersjes W et al. Follow-up of Crohn's disease: can hydro-MRI replace fractionated gastrointestinal passage examination? Fortschr Röntgenstr 1997; 166: 389-396

3 Vilela EG, Torres HO, Martins FP et al. Evaluation of inflammatory activity in Crohn's disease and ulcerative colitis. World J Gastroenterol 2012; 18: $872-881$

4 Girlich C, Schacherer D, Jung EM et al. Comparison between a clinical activity index (Harvey-Bradshaw-Index), laboratory inflammation markers and quantitative assessment of bowel wall vascularization by contrast-enhanced ultrasound in Crohn's disease. Eur J Radiol 2012; 81: $1105-1109$

5 Kambadakone AR, Prakash P, Hahn PF et al. Low-dose CT examinations in Crohn's disease: Impact on image quality, diagnostic performance, and radiation dose. American journal of roentgenology 2010; 195: $78-88$

6 Fletcher JG. CT enterography technique: theme and variations. Abdom Imaging 2009; 34: 283-288

7 Villa C, Pompili G, Franceschelli $G$ et al. Role of magnetic resonance imaging in evaluation of the activity of perianal Crohn's disease. Eur J Radiol 2012; 81: 616-622

8 Schreyer AG, Seitz J, Feuerbach S et al. Modern imaging using computer tomography and magnetic resonance imaging for inflammatory bowel disease (IBD) AU1. Inflamm Bowel Dis 2004; 10: 45-54

9 Hansmann HJ, Hess T, Hahmann M et al. MRI in chronic inflammatory bowel disease. Fortschr Röntgenstr 2001; 173: 4-11

10 Kern A, Schunk K, Kessler M et al. Hydro-MRI for abdominal diagnostics in children. Fortschr Röntgenstr 2001; 173: 984-990

11 Schunk K, Kern A, Heussel CP et al. Hydro-MRT with fast sequences in Crohn's disease: a comparison with fractionated gastrointestinal passage. Fortschr Röntgenstr 1999; 170: 338 - 346

12 Schreyer AG, Ludwig D, Koletzko S et al. Updated German S3-guideline regarding the diagnosis of Crohn's disease - implementation of radiological modalities. Fortschr Röntgenstr 2010; 182: 116-121

13 Hoffmann JC, Autschbach F, Bokemeyer B et al. Short version of the updated German S3 (level 3) guideline on diagnosis and treatment of Crohn's disease. Dtsch Med Wochenschr 2008; 133: 1924-1929

14 Van Assche G, Dignass A, Reinisch $W$ et al. The second European evidence-based Consensus on the diagnosis and management of Crohn's disease: Special situations. J Crohns Colitis 2010; 4: 63-101

15 Masselli G, Casciani E, Polettini E et al. Comparison of MR enteroclysis with MR enterography and conventional enteroclysis in patients with Crohn's disease. Eur Radiol 2008; 18: 438 - 447

16 Schreyer AG, Geissler A, Albrich $H$ et al. Abdominal MRI after enteroclysis or with oral contrast in patients with suspected or proven Crohn's disease. Clin Gastroenterol Hepatol 2004; 2: 491 - 497

17 Horsthuis K, Bipat S, Bennink RJ et al. Inflammatory bowel disease diagnosed with US, MR, scintigraphy, and CT: meta-analysis of prospective studies. Radiology 2008; 247: 64-79

18 Menys A, Atkinson D, Odille $F$ et al. Quantified terminal ileal motility during MR enterography as a potential biomarker of Crohn's disease activity: a preliminary study. Eur Radiol 2012; 22: 2494-2501

19 Horsthuis K, Bipat S, Stokkers PC et al. Magnetic resonance imaging for evaluation of disease activity in Crohn's disease: a systematic review. Eur Radiol 2009; 19: 1450-1460

20 Egger L, Fikentscher T, Poschenrieder F et al. Klinischer Stellenwert der Durchleuchtung der Magen-Darm-Passage (MDP) an einem Universitätsklinikum. Fortschr Röntgenstr 2012; 184: 893-898

21 Schill G, Iesalnieks I, Haimerl M et al. Assessment of disease behavior in Crohn's disease patients by MR-enterography. Inflamm Bowel Dis 2013; 19: 983 - 990

22 Schreyer AG, Menzel C, Friedrich C et al. Comparison of high-resolution ultrasound and MR-enterography in patients with inflammatory bowel disease. World J Gastroenterol 2011; 17: 1018-102523 
23 Jensen MD, Ormstrup T, Vagn-Hansen $C$ et al. Interobserver and intermodality agreement for detection of small bowel Crohn's disease with MR enterography and CT enterography. Inflam Bowel Dis 2011; 17: $1081-1088$

24 Panner J, Schuetz GM, Hamm B et al. Eine systematische Anleitung zum Lesen und Interpretieren diagnostischer Genauigkeitsstudien. Fortschr Röntgenstr 2011; 183: 909-912

25 Schleder S, Dendl LM, Pawlik M et al. Sequenz-Evaluation für die MREnterografie für Patienten mit Morbus Crohn. Fortschr Röntgenstr 2013; 185: $440-445$

26 Schreyer AG, Scheibl K, Heiss P et al. MR colonography in inflammatory bowel disease. Abdom Imaging 2006; 31: $302-307$

27 Friedrich C, Fajfar A, Pawlik M et al. Magnetic resonance enterography with and without biphasic contrast agent enema compared to conventional ileocolonoscopy in patients with Crohn's disease. Inflamm Bowel Dis 2012; 18 : $1842-1848$

28 Schreyer AG, Golder S, Scheibl K et al. Dark lumen magnetic resonance enteroclysis in combination with MRI colonography for whole bowel assessment in patients with Crohn's disease: first clinical experience. Inflamm Bowel Dis 2005; 11: 388 - 394
29 Schreyer AG, Rath HC, Kikinis $R$ et al. Comparison of magnetic resonance imaging colonography with conventional colonoscopy for the assessment of intestinal inflammation in patients with inflammatory bowel disease: a feasibility study. Gut 2005; 54: 250-256

30 Golder SK, Schreyer AG, Endlicher E et al. Comparison of capsule endoscopy and magnetic resonance (MR) enteroclysis in suspected small bowel disease. Int J Colorectal Dis 2006; 21: 97 - 104

31 Schmidt S, Lepori D, Meuwly JY et al. Prospective comparison of MR enteroclysis with multidetector spiral-CT enteroclysis: interobserver agreement and sensitivity by means of "sign-by-sign" correlation. Eur Radiol 2003; 13: 1303-1311

32 Schreyer AG, Hoffstetter P, Daneschnejad $M$ et al. Comparison of conventional abdominal CT with MR-enterography in patients with active Crohn's disease and acute abdominal pain. Academic Radiology 2010; 17: $352-357$

33 Gourtsoyianni S, Papanikolaou N, Amanakis E et al. Crohn's disease lymphadenopathy: MR imaging findings. Eur J Radiol 2009; 69: $425-428$

34 Malago R, Manfredi R, Benini L et al. Assessment of Crohn's disease activity in the small bowel with MR-enteroclysis: clinico-radiological correlations. Abdom Imaging 2008; 33: 669-675 